\title{
Skrining Stres Pascatrauma pada Remaja dengan Menggunakan Post Traumatic Stress Disorder Reaction Index
}

Putu Dian Savitri Irawan, ' Soetjiningsih," IGA Trisna Windiani, ${ }^{*}$ I Gst Ag Sugitha Adnyana, ${ }^{*}$ IGA Endah Ardjana* "Bagian Ilmu Kesehatan Anak, "Bagian Ilmu Kedokteran Jiwa Fakultas Kedokteran Universitas Udayana, Denpasar

Latar belakang. Stres pascatrauma (post traumatic stress disorder atau PTSD) merupakan suatu gangguan psikiatri fungsi sosial seseorang. Universitas California Los Angeles (UCLA) mengembangkan serangkaian self-report kuesioner yang disebut PTSD Reaction Index (PTSD-RI) untuk deteksi dini gangguan tersebut. Namun, kuesioner tersebut belum pernah digunakan di Indonesia.

Tujuan. Mengetahui reliabilitas instrumen post traumatic stress disoder reaction index (PTSD-RI) versi remaja, prevalensi, serta faktor yang berhubungan dengan PTSD.

Metode. Penelitian potong lintang dilaksanakan di enam SMUN di Denpasar. Digunakan kuesioner PTSD-RI versi remaja yang telah diterjemahkan ke dalam Bahasa Indonesia. Digunakan uji $\alpha$ Cronbach untuk menilai reliabilitas PTSD-RI. Analisis statistik menggunakan uji chi-square dan multivariat regresi logistik.

Hasil. Terdapat 300 pelajar SMUN yang mengikuti penelitian. Enam puluh orang (20\%) dengan tersangka PTSD. Reliabilitas PTSD-RI baik (koefisien $\alpha$ 0,94). Tipe kepribadian tertutup sebagai faktor risiko PTSD [RP 3,55 (IK95\% 1,46-8,66), p=0,01]. Keluarga yang harmonis [RP 0,35 (IK95\% 0,08-0,78), p=0,02], adanya dukungan keluarga [RP 0,13 (IK95\% 0,03-0,50), p=0,01], adanya dukungan sosial [RP 0,25 (IK95\% 0,09-0,68), p=0,01], serta trauma tunggal [RP 0,02 (IK95\% 0,14- 0,82), p=0,01] berperan sebagai faktor protektif PTSD.

Kesimpulan. Instrumen PTSD-RI memiliki reliabilitas yang baik sehingga dapat digunakan di Indonesia. Prevalensi PTSD pada remaja di Denpasar sebesar 20\%. Sari Pediatri 2016;17(6):441-5.

Kata kunci : post-traumatic stress disorder, prevalensi, remaja

\section{Post Traumatic Stress Disorder Screening in Adolescent Using Post Traumatic Stress Disorder Reaction Index}

Putu Dian Savitri Irawan, 'Soetjiningsih," IGA Trisna Windiani," I Gst Ag Sugitha Adnyana,, IGA Endah Ardjana*

Background. Post-traumatic stress disorder (PTSD) is a psychiatric disorder that can impair an individual's social function. University of California Los Angeles (UCLA) have developed a series of self-report instruments named PTSD Reaction Index (PTSD-RI) to screen PTSD. Unfortunately, these instruments have never been used in Indonesia.

Objective. To determine the reliability of Post-Traumatic Stress Disorder Reaction Index (PTSD-RI) adolescent version, prevalence and factors associated with PTSD in public senior high school students in Denpasar, Bali, Indonesia.

Methods. We conducted a cross sectional study among six public senior high schools students in Denpasar. Questionnaire PTSD$\mathrm{RI}$ adolescent version was translated into Indonesian language. Reliability of PTSD-RI was determined using alpha Cronbach test. Statistical analysis was done using Chi-Square test and multivariate logistic regression.

Results. A total of 300 eligible students were enrolled as study participants. Sixty students (20\%) were found to have suspected PTSD. The reliability of PTSD-RI was good (alpha coefficient 0.94$)$. Multivariate analysis showed that introvert personality increased the possibility of having PTSD [PR 3.55 (CI 95\% 1.46 to 8.66), P=0.01]. On the other hand, strong family relation [PR 0.35 (CI 95\% 0.08 to 0.78 ), $\mathrm{P}=0.02$ ], family support [PR 0.13 (CI 95\% 0.03 to 0.50 ), $\mathrm{P}=0.01$ ], social support [PR 0.25 (CI $95 \% 0.09$ to 0.68 ), $\mathrm{P}=0.01$, and only single traumatic event [PR 0.02 (CI 95\% 0.14 to 0.82 ), $\mathrm{P}=0.01$ ] acted as protective factors.

Conclusion. Post-Traumatic Stress Disorder Reaction Index (PTSD-RI) adolescent version has a good reliability and could be used in Indonesia. The prevalence of PTSD among adolescents in Denpasar was 20\%. Sari Pediatri 2016;17(6):441-5.

Keywords: post-traumatic stress disorder, prevalence, adolescent

\footnotetext{
Alamat korespondensi: Prof. Dr. Soetjiningsih, SpA(K). Dr. Putu Dian Savitri. Bagian IKA FK UNUD/RS Sanglah. Jl. P. Nias, Denpasar. Tel. +62-361-232404 / 244038. E-mail:prof_soetjiningsih@yahoo.com
} 
Putu Dian Savitri Irawan dkk: Skrining stres pascatrauma pada remaja dengan menggunakan PTSD-RI

S tres pascatrauma (post traumatic stress disorder atau PTSD) merupakan suatu gangguan psikiatri yang bersifat kompleks, ${ }^{1}$ dapat mengenai semua kelompok usia, ${ }^{2}$ serta dapat mengganggu fungsi sosial seseorang. ${ }^{1}$ Remaja merupakan kelompok yang paling rentan untuk mengalami gangguan tersebut. ${ }^{3,4}$ Penelitian mengenai prevalensi PTSD pada remaja masih terbatas. ${ }^{5}$

Gangguan aspek kognitif, munculnya sikap dan perilaku yang cenderung merusak, baik bagi dirinya sendiri maupun lingkungan, merupakan dampak yang dapat ditimbulkan oleh PTSD bagi remaja. ${ }^{3,6}$ Oleh sebab itu, skrining PTSD memegang peranan yang sangat penting. ${ }^{4}$ Namun sampai saat ini, belum tersedia instrumen skrining gangguan tersebut di Indonesia.

Penelitian ini bertujuan untuk mengetahui reliabilitas dari kuesioner PTSD-RI versi remaja yang telah diterjemahkan ke dalam bahasa Indonesia, prevalensi, dan faktor yang berhubungan dengan gangguan tersebut pada pelajar SMUN di Denpasar.

\section{Metode}

Penelitian dilaksanakan selama bulan November sampai Desember 2014 dengan rancangan potong lintang analitik. Data diperoleh dari kuesioner yang diisi oleh pelajar di enam SMUN di Denpasar (SMUN 1, SMUN 2, SMUN 3, SMUN 5, SMUN 7, dan SMUN 8 Denpasar). Pemilihan SMUN dilakukan secara purposive karena mudah dijangkau. Besar subjek dengan memperhitungkan nilai $\alpha 0,1$ dan power penelitian $90 \%$ didapatkan jumlah subjek minimal 288 pelajar. Pada penelitian melibatkan 300 orang subjek. Kriteria inklusi adalah pelajar SMUN yang bersekolah di Denpasar dan setuju untuk ikut serta dalam penelitian. Kriteria eksklusi apabila data pada kuesioner tidak lengkap.

Pada setiap SMUN dipilih 50 orang pelajar berdasarkan probability sampling (systematic sampling), yakni 16 orang kelas X, 17 kelas XI, dan 17 kelas XII. Subjek dipilih berdasarkan rumus $\mathrm{x} / \mathrm{n}$ dengan $\mathrm{x}$ adalah jumlah subjek diperlukan; $\mathrm{n}$ adalah jumlah total pelajar. Sebagai contoh, bila jumlah total pelajar kelas XII di sebuah SMUN berjumlah 150 orang dan dibutuhkan 16 subjek maka setiap pelajar ke-10 diikutsertakan dalam penelitian. Penentuan nomor absensi awal dilakukan secara acak dengan menjatuhkan ujung pensil pada lembar absensi pelajar. Bila nomor awal adalah nomor absen 10, maka pelajar dengan nomor absen 10, 20, 30 dan seterusnya diikutsertakan dalam penelitian.

Instrumen yang digunakan adalah kuesioner PTSD Reaction Index (PTSD-RI) versi remaja oleh Rodriguez dkk dari University National Center for Child Traumatic Stress di Universitas California Los Angeles (UCLA) untuk skrining PTSD. Kuesioner tersebut telah diterjemahkan ke dalam bahasa Indonesia atas seijin UCLA. Kuesioner tersebut mencakup variabel jenis kelamin, tipe keluarga, dukungan keluarga, dukungan sosial, tipe kepribadian, serta jumlah trauma. Penggunaan titik potong $\geq 38$ pada symptom severity rating scale PTSD-RI memiliki sensitivitas 93\% dan spesifisitas 87\% dalam mendeteksi PTSD. ${ }^{7}$ Variabel keharmonisan keluarga diukur menggunakan kuesioner oleh Stinet dan DeFrain dengan reliabilitas yang baik (dilaporkan memiliki koefisien alpha 0,89 ). Skor total $\geq 50$ menyatakan persepsi positif adanya keharmonisan keluarga. ${ }^{8}$ Variabel yang diteliti dalam penelitian, yaitu jenis kelamin, keharmonisan keluarga, tipe keluarga, dukungan keluarga, dukungan sosial, tipe kepribadian, serta jumlah trauma.

Analisis data digunakan program komputer. Uji alpha Cronbach untuk menilai reliabilitas kuesioner PTSD RI. Titik potong $\alpha$ Cronbach yang digunakan adalah 0,80 untuk menyatakan reliabilitas alat ukur tersebut baik. ${ }^{9}$ Hubungan dan parameter kekuatan antar variabel dinilai melalui Uji chi-square dengan nilai $\mathrm{p}<0,05$ dianggap bermakna dan rasio prevalens (RP). Analisis multivariat yang digunakan adalah regresi logistik. Penelitian ini telah mendapat ijin kelaikan etik dan persetujuan melakukan penelitian dari Komite Etik Penelitian Fakultas Kedokteran Universitas Udayana/ Rumah Sakit Umum Pusat Sanglah Denpasar.

\section{Hasil}

Tigaratus pelajar mengikuti penelitian. Semua subjek mengisi kuesioner dengan lengkap sehingga subjek yang benar diteliti berjumlah 300 orang, yakni 107 (35,7\%) laki-laki dan 193 (64,3\%) perempuan. Rentang usia adalah 14 hingga 18 tahun. Nilai koefisien $\alpha$ Cronbach kuesioner PTSD-RI didapatkan 0,94 . Hasil tersebut menunjukkan bahwa reliabilitas dari alat ukur tersebut baik. Terdapat 60 (20\%) didapatkan dengan tersangka PTSD. Median skor total adalah 25 dengan nilai minimum 1 dan nilai 
maksimum 68. Karakteristik subjek penelitian tertera pada Tabel 1.

Tiga jenis kejadian traumatis terbanyak yang dialami subjek penelitian, antara lain mengalami kekerasan fisik di dalam rumah (26,9\%), mendengar berita kematian atau kecelakaan serius menimpa orang yang dicintai $(16,2 \%)$, serta melihat anggota keluarga

Tabel 1. Karakteristik subjek penelitian

\begin{tabular}{lc}
\hline Variabel & $\mathrm{N}=300$ \\
\hline $\begin{array}{l}\text { Jenis kelamin, n (\%) } \\
\quad \text { Perempuan }\end{array}$ & $193(64,3)$ \\
Keharmonisan keluarga, n (\%) & \\
$\quad$ Positif & $256(85,3)$ \\
$\quad$ Negatif & $44(14,7)$ \\
Tipe keluarga, n (\%) & \\
$\quad$ Keluarga inti & $274(91,3)$ \\
$\quad$ Keluarga dengan orangtua tunggal & $26(8,7)$ \\
Dukungan keluarga, n (\%) & \\
$\quad$ Ya & $261(87)$ \\
$\quad$ Tidak & $39(13)$ \\
Dukungan sosial , n (\%) & \\
$\quad$ Ya & $243(81)$ \\
$\quad$ Tidak & $57(19)$ \\
Kepribadian, n (\%) & \\
$\quad$ Terbuka & $176(58,7)$ \\
$\quad$ Tertutup & $124(41,3)$ \\
Jumlah trauma, n (\%) & \\
$\quad$ Tunggal, n (\%) & $162(54)$ \\
$\quad$ Multipel, n (\%) & $138(46)$ \\
\hline
\end{tabular}

mengalami kekerasan fisik di dalam rumah (10,9\%).

Pada analisis bivariat (Tabel 2) didapatkan semua variabel yang diteliti (kecuali jenis kelamin) berhubungan dengan PTSD dengan nilai $\mathrm{p}<0,0001$. Variabel bebas yang bertindak sebagai faktor risiko adalah tipe kepribadian tertutup, sementara variabel bebas yang lain bertindak sebagai faktor protektif. Analisis multivariat yang digunakan dalam penelitian adalah regresi logistik seperti yang tertera pada Tabel 3. Setelah dilakukan analisis multivariat, didapatkan faktor yang berhubungan dengan PTSD adalah tipe kepribadian tertutup sebagai faktor risiko sementara keluarga harmonis, dukungan keluarga, dukungan sosial, serta trauma tunggal bertindak sebagai faktor protektif.

\section{Pembahasan}

Remaja merupakan kelompok yang paling rentan dan berisiko tinggi untuk mengalami PTSD., ${ }^{3,4}$ Masa remaja merupakan masa terjadinya banyak perubahan baik dalam hal fisik maupun emosional. Pada tahun 2013, Australian Centre for Posttraumatic Mental Health melaporkan bahwa lebih dari 6\% anak dan remaja di Australia mengalami PTSD. ${ }^{10}$ Pada penelitian kami prevalensi PTSD didapatkan 20\%. Perbedaan epidemiologi antar negara tersebut dapat terjadi akibat perbedaan instrumen deteksi dini dan diagnosis PTSD yang digunakan, perbedaan tingkat perkembangan

Tabel 2. Hubungan beberapa faktor risiko dengan PTSD

\begin{tabular}{|c|c|c|c|c|c|c|}
\hline \multicolumn{2}{|l|}{ Variabel } & Tersangka PTSD & Bukan PTSD & $\mathrm{p}$ & $\mathrm{RP}$ & IK 95\% \\
\hline \multirow[t]{2}{*}{ Jenis kelamin $(n, \%)$} & Perempuan & $45(23,3)$ & $148(76,7)$ & 0,05 & 1,87 & $0,98-3,54$ \\
\hline & Laki-laki & $15(14,0)$ & $92(86,0)$ & & & \\
\hline \multirow[t]{2}{*}{ Keharmonisan keluarga $(\mathrm{n}, \%)$} & Positif & $28(10,9)$ & $228(89,0)$ & $<0,0001$ & 0,05 & $0,02-0,10$ \\
\hline & Negatif & $32(72,7)$ & $12(27,3)$ & & & \\
\hline \multirow[t]{3}{*}{ Tipe keluarga $(\mathrm{n}, \%)$} & Keluarga inti & $38(13,9)$ & $236(86,1)$ & $<0,0001$ & 0,03 & $0,01-0,09$ \\
\hline & Orangtua tunggal & & & & & \\
\hline & & $22(84,6)$ & $4(15,4)$ & & & \\
\hline \multirow[t]{2}{*}{ Dukungan keluarga (n,\%) } & Ya & $27(10,3)$ & $234(89,7)$ & $<0,0001$ & 0,02 & $0,01-0,05$ \\
\hline & Tidak & $33(84,6)$ & $6(15,4)$ & & & \\
\hline \multirow{2}{*}{ Dukungan sosial $(\mathrm{n}, \%)$} & Nyaman & $25(10,3)$ & $218(89,7)$ & $<0,0001$ & 0,07 & $0,04-0,14$ \\
\hline & Tidak nyaman & $35(61,4)$ & $22(38,6)$ & & & \\
\hline \multirow[t]{2}{*}{ Kepribadian $(\mathrm{n}, \%)$} & Tertutup & $47(37,9)$ & $77(62,1)$ & $<0,0001$ & 7,65 & $3,91-14,98$ \\
\hline & Terbuka & $13(7,4)$ & $163(92,6)$ & & & \\
\hline \multirow{2}{*}{ Jumlah trauma $(\mathrm{n}, \%)$} & Tunggal & $13(8,0)$ & $149(92,0)$ & $<0,0001$ & 0,17 & $0,09-0,33$ \\
\hline & Multipel & $47(34,0)$ & $91(66,0)$ & & & \\
\hline
\end{tabular}

$\mathrm{n}=$ jumlah subjek ; $\mathrm{p}=$ probabilitas; $\mathrm{RP}=$ risiko prevalen; $\mathrm{IK}=$ interval kepercayaan 
Putu Dian Savitri Irawan dkk: Skrining stres pascatrauma pada remaja dengan menggunakan PTSD-RI

Tabel 3. Analisis multivariat variabel yang berhubungan dengan PTSD

\begin{tabular}{lccc}
\hline Variabel & $\mathrm{p}$ & $\mathrm{RP}$ & $\mathrm{IK} 95 \%$ \\
\hline Jenis kelamin & 0,09 & 2,18 & $0,87-5,47$ \\
Keharmonisan keluarga & 0,02 & 0,35 & $0,08-0,78$ \\
Tipe keluarga & 0,52 & 0,50 & $0,06-4,03$ \\
Dukungan keluarga & 0,01 & 0,13 & $0,03-0,50$ \\
Dukungan sosial & 0,01 & 0,25 & $0,09-0,68$ \\
Kepribadian & 0,01 & 3,55 & $1,46-8,66$ \\
Jumlah trauma & 0,02 & 0,34 & $0,14-0,82$ \\
\hline
\end{tabular}

individu, latar belakang keluarga, sosial budaya, tingkat ekonomi, serta agama. ${ }^{4}$

Kejadian traumatis yang paling banyak dialami oleh pelajar adalah mengalami kekerasan fisik oleh orangtua $(26,9 \%)$. Hasil penelitian kami menunjukkan bahwa tindakan kekerasan justru seringkali dilakukan oleh orang terdekat, yakni keluarga. Hasil serupa juga dijumpai pada penelitian oleh Komisi Perlindungan Anak Indonesia (KPAI) pada tahun 2012 di 9 provinsi di Indonesia. Dari total 2113 responden, 91\% anak menyatakan pernah mendapatkan perlakuan tindak kekerasan dalam keluarga. ${ }^{11}$

Jenis kelamin perempuan tidak terbukti sebagai faktor risiko PTSD. Hubungan antara jenis kelamin dengan PTSD telah banyak diteliti sebelumnya dan menunjukkan hasil yang inkonsisten. ${ }^{4}$ Berdasarkan The National Comorbidity Survey (NCS), prevalensi PTSD lebih tinggi pada perempuan $(10,3 \%)$ dibandingkan laki-laki $(2,8 \%) .{ }^{4}$ Hasil yang berbeda dilaporkan oleh Breslau dkk, ${ }^{4}$ yang menyatakan prevalensi PTSD di Amerika Serikat pada tahun 2004 lebih banyak pada remaja laki-laki $(87,2 \%)$. Adanya perbedaan respons adaptif antara perempuan dan laki-laki terhadap suatu kejadian traumatis diduga berkaitan dengan perbedaan respons adaptif. ${ }^{12}$

Penelitian kami menunjukkan adanya keharmonisan dalam keluarga, dukungan keluarga, serta dukungan sosial yang merupakan faktor protektif PTSD. Keluarga, seperti yang disebutkan Bronfenbrenner, ${ }^{13}$ merupakan lapisan pengaruh terdekat terhadap perkembangan seseorang. Kualitas dan hubungan dengan orangtua akan memengaruhi individu dalam melihat diri sendiri dan memunculkan sikap ketika berhadapan dengan suatu masalah. ${ }^{13}$ Dukungan sosial, seperti yang diungkapkan oleh Wheaton, ${ }^{14}$ berfungsi sebagai "stress buffers" yang dapat melindungi seseorang dari stres maupun pengaruh buruk suatu kejadian traumatis.
Tipe kepribadian tertutup berperan sebagai faktor risiko PTSD. Hasil penelitian kami sesuai dengan teori kepribadian Jung yang menyatakan bahwa individu dengan kepribadian tertutup atau introvert memiliki karakteristik kesulitan berinteraksi dan beradaptasi baik dengan lingkungan maupun saat menghadapi suatu masalah. ${ }^{15,16}$

Penelitian kami menghasilkan data epidemiologi yang penting mengenai PTSD pada pelajar SMUN di Kotamadya Denpasar. Penelitian kami juga menggunakan kuesioner PTSD-RI versi remaja yang belum pernah digunakan di Indonesia. Kekuatan pada penelitian terletak pada rentang interval kepercayaan yang sempit dan mencerminkan power yang cukup besar $(90 \%)$ serta jumlah subjek penelitian yang memadai. Subjek dipilih dengan cara probability sampling untuk mengurangi adanya bias inklusi. Kuesioner yang digunakan tidak mencantumkan nama maupun nama sekolah yang bersangkutan untuk menjaga kerahasiaan subjek serta mengurangi adanya bias subjek (recall bias).

Keterbatasan penelitian kami, antara lain rancangan penelitian potong lintang dan tidak ada prosedur tindak lanjut atau follow up. Data diperoleh melalui kuesioner yang diisi langsung oleh subjek sehingga sangat dipengaruhi oleh kejujuran, perasaan, dan emosi subjek saat pengisian kuesioner. Kami juga tidak meneliti beberapa faktor risiko lain yang bersifat sangat sensitif dan pribadi sehingga pengumpulan data melalui wawancara mendalam dirasakan lebih tepat.

\section{Kesimpulan}

Kuesioner PTSD-RI memiliki reliabilitas yang baik sehingga dapat digunakan di Indonesia. Prevalensi PTSD pada pelajar SMUN di Kotamadya Denpasar didapatkan 20\%. Tipe kepribadian tertutup merupakan faktor risiko PTSD, sementara faktor 
protektif, antara lain keluarga yang harmonis, adanya dukungan keluarga, dukungan sosial, serta trauma tunggal.

\section{Daftar pustaka}

1. David T, Andy PS, Richard MS, Serpell L, Andy PF. A meta-analysis of risk factors for post-traumatic stress disorder in children. Clin Psychol Rev 2012;32:122-38.

2. Terence M, Keane. The epidemiology of post-traumatic stress disorder: some comments and concerns. The National Research for Post-Traumatic Stress Disorder 1990;1:1-3.

3. John AF. PTSD research quarterly: the epidemiology of trauma and trauma related disorders in children and youth. The National Center for PTSD 2008;19:1-3.

4. Saxe G, Douglas V, Barry Z. PTSD research quarterly: traumatic stress in injured and ill children. The National Center for PTSD 2003;14:1-3.

5. Van der Oord S, Lucassen S, Van Emmerik AAP, Emmelkamp PMG. Treatment of post-traumatic stress disorder in children using cognitive behavioural writing therapy. Clin Psychol Psychother 2009;10:1-9.

6. Kaminer D, Seedat S, Stein J. Post-traumatic stress disorder in children. World Psychiatry 2005;4:121-4.

7. Steinberg AM, Brymer MJ, Decker KB, Pynoos RS. The university of California at Los Angeles post-traumatic stress disorder reaction index. Curr Psychiatry Reports 2004;6:96-100.

8. Maria U. Peran persepsi keharmonisan keluarga dan konsep diri terhadap kecenderungan kenakalan remaja, tesis. Yogyakarta: Universitas Gadjah Mada, 2007.

9. Murti B. Validitas dan reliabilitas pengukuran. Surakarta: Matrikulasi Program Studi Doktoral Fakultas Kedokteran UNS; 2011.h.1-19.

10. Fatimah L. Hubungan persepsi anak terhadap keharmonisan keluarga dan pola asuh orangtua dengan motivasi belajar, tesis. Surakarta: Universitas Sebelas Maret Surakarta, 2010.

11. Sholeh AN, penyunting. Media digital, pemenuhan hak, dan perlindungan anak. Prosiding dari Seminar Internasional Penggunaan Media Digital di Kalangan Anak dan Remaja; Jakarta,Indonesia; 18 Februari 2014. Jakarta: Kementerian Komunikasi dan Informatika; 2014.

12. Bruce D, Perry MD. Stress, trauma and post-traumatic stress disorders in children. Diakses pada 29 Maret 2016. Didapat dari: https://childtrauma.org/wp-content/ uploads/2013/11/PTSD_Caregivers.pdf.

13. Afiah FN, Purnamasari SE. Hubungan antara keharmonisan keluarga dengan sikap terhadap seks pranikah pada remaja, tesis. Yogyakarta: Fakultas Psikologi Universitas Wangsa Manggala, 2010.

14. Cohen S. Stress, social support, and disorder. Dalam: Veiel HOF, Baumann U, penyunting. The meaning and measurement of social support. Edisi pertama. New York: Hemisphere Press;1992.h.109-25.

15. Jung CG. The analytical psychology of Carl Gustav Jung. Diakses pada 29 Maret 2016. Didapat dari: http://www. matrixmeditations.info/bonusJung.pdf.

16. Blutner R, Hochnadel E. Two qubits for C.G Jung's theory of personality. Cognitive Systems Research 2010;11:24359. 